\title{
Research Progress of Gadolinium in Heat Resistant Magnesium alloys
}

\author{
Jinglong Yan ${ }^{1,}$, Q Quan-an $\mathrm{Li}^{1,2,{ }^{*}}$, Xiaoya Chen ${ }^{1}$, Yao Zhou ${ }^{1}$ \\ ${ }^{1}$ School of Materials Science and Engineering, Henan University of Science and Technology, \\ Luoyang 471023, China \\ ${ }^{2}$ Collaborative Innovation Center of Nonferrous Metals, Henan Province, Luoyang 471023, China \\ ahkdyjl@163.com *q-ali@163.com
}

Keywords: Magnesium alloys; Gd; Heat resistance; Strengthening mechanisms

\begin{abstract}
This paper expounds the characteristics of Gd and Mg-Gd binary alloys, Introduces the mechanism of Gd addition on the heat resistant magnesium alloys. Reviewed the research progress in magnesium alloys containing Gd on mechanical properties at room temperature and high temperature, and prospected their development prospects.
\end{abstract}

\section{Introduction}

Magnesium is the lightest metal structure materials in the engineering application, with a density only $2 / 3$ of that of aluminum and $1 / 4$ of carbon steels. At the same time, magnesium alloys have high specific strength, high specific modulus, high damping, electromagnetic shielding, a series of unique advantage of excellent casting, machineability and availability. It is widely applied in the industrial field of aerospace, defense, automotive, electronic communications, computer, household appliances etc. [1]. Therefore, magnesium is known as the "green engineering materials in twenty-first Century" [2]. But the heat resistant properties of magnesium alloys are poor, when temperature rises, the strength and creep resistance greatly decreased, which limits their application.

Alloying is improvement of magnesium alloys heat resistance properties of the most effective means[3]. RE (such as $\mathrm{Gd}, \mathrm{Y}, \mathrm{Nd}$ ) is the important elements used to improve the heat resistant properties of magnesium alloys, among them Mg-Gd alloys have the relatively stable of low creep rate and higher creep resistance, the excellent mechanical properties at room temperature and high temperature even more than the commercially successful Mg-Y-RE series WE54, WE43 alloy, causing widespread concern in domestic and foreign researchers.

\section{The main effect of RE in magnesium alloys}

Similar crystal structure of rare-earth and magnesium in magnesium alloys, the same as the close packed six party structure, so it has high solid solubility. Addition of RE in magnesium alloys melt can protect, purifying melt, improving the casting process, and refinement of metamorphism. Rare earth elements into solid solution formed magnesium alloy matrix, played the solid solution strengthening effect. During aging, it formed the dispersion of precipitated phase, which can improve the strength and creep resistance of magnesium alloys.

\section{The characteristics of Gd and Mg-Gd binary alloy}

$\mathrm{Ga}$ is a typical representative of the heavy RE elements, with the atomic weight of 157.25, the density of $7.89 \mathrm{~g} / \mathrm{cm}^{3}$ and the melting point of $1312^{\circ} \mathrm{C}$. The solid solubility of Gd in magnesium alloys is larger, and with the decrease of temperature decreases rapidly $\left(548^{\circ} \mathrm{C}\right.$ for a maximum of $23.5 \%, 200^{\circ} \mathrm{C}$ only for $3.82 \%$ ), and it can compound with $\mathrm{Mg}$ reaction to produce $\mathrm{Mg}_{5} \mathrm{Gd}, \mathrm{Mg}_{3} \mathrm{Gd}$, $\mathrm{Mg}_{2} \mathrm{Gd}, \mathrm{MgGd}$ and other high thermal stability, produce the excellent solid solution strengthening and aging strengthening effect, so that the Mg-Gd alloys have excellent mechanical properties at room and high temperature[4]. 
Drits[5,6]found that Mg-22Gd alloy at room temperature tensile strength reaches above $400 \mathrm{MPa}$, and its high temperature strength is superior to the traditional heat-resistant magnesium alloys WE54, its heat-resistant temperature reached $350^{\circ} \mathrm{C}$ [7-9].

\section{Strengthening mechanisms of Gd on the heat resistant magnesium alloys}

The present study shows that, adding proper amount of Gd magnesium alloys can improve the high temperature creep, and make its strength significantly improved. Generally, the main mechanism of Gd to improve the heat resistant properties of magnesium alloys is fine grain strengthening, solution strengthening and grain boundary strengthening.

\section{Fine grain strengthening}

According to the Hall-Petch formul, the magnesium alloys in the K value of $280 \sim 320 \mathrm{MPa} \cdot \mu \mathrm{m}^{1 / 2}$, the fine grain strengthening is one of the important means to improve the strength of magnesium alloys[10]. Because the atomic radius of $\mathrm{Gd}$ and $\mathrm{Mg}$ are similar $\left(\mathrm{r}_{\mathrm{Mg}}=0.16 \mathrm{~nm}, \mathrm{r}_{\mathrm{Gd}}=0.18 \mathrm{~nm}\right)$, and are densely arranged six party structure, the lattice constant is very close $\left(\mathrm{a}_{\mathrm{Gd}}=0.363 \mathrm{~nm}\right.$, $\left.\mathrm{C}_{\mathrm{Gd}}=0.576 \mathrm{~nm}, \mathrm{a}_{\mathrm{Mg}}=0.323 \mathrm{~nm}, \mathrm{c}_{\mathrm{Mg}}=0.520 \mathrm{~nm}\right)$, according to the crystal surface lattice correspondence theory, Gd can be the heterogeneous nucleation core of $\alpha-\mathrm{Mg}$, and $\alpha-\mathrm{Mg}$ can greatly improve the nucleation probability, hinder grain growth, so Gd has good fine grain strengthening effect on magnesium alloys.

\section{Solid solution strengthening}

By the Hume-Rothery rules that, when solute and solvent radius difference less than $15 \%$ to

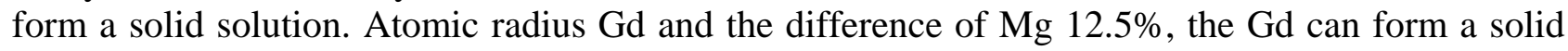
solution with $\mathrm{Mg}$, the solid solubility can reach a maximum of $23.5 \%$ (mass fraction), so as to play a role of the excellent solid solution strengthening effect[11]. A part of Gd in magnesium alloys solid solution in the $\alpha-\mathrm{Mg}$, forming the solid solution, another part of forming the rare earth compounds. These compounds have high thermal stability and thermal hard, and not easy to precipitate growth, can improve the high temperature strength of magnesium alloys.

\section{Grain boundary strengthening}

Gd formed stable intermetallic compound $\mathrm{Mg}_{5} \mathrm{Gd}$ in magnesium alloys solidification process. The compounds with high melting point $\left(640^{\circ} \mathrm{C}\right)$, high stability and other characteristics, is a compound of small particles distributed in the grain boundary and inside, high temperature can inhibit the pinning the grain boundaries and grain boundary sliding, and hinder the movement of dislocations, strengthens the alloy matrix, and can obviously improve the high temperature properties of magnesium alloys and the creep resistance properties.

\section{Application and research progress of $\mathrm{Gd}$ in heat resistant magnesium alloys}

At present, magnesium alloys research mainly concentrated in the Mg-Al, Mg-Zn, Mg-RE series. Rare earth element Gd can be used as alloy elements individually adding magnesium alloys, and can also be combined addition with other RE or alkaline earth elements, also can be with a variety of other elements (rare earth and alkaline earth and other alloy elements) composite to join, so Gd can link comprehensively the heat-resistant magnesium alloys alloying up to widely used in heat resistant magnesium alloys.

\section{Mg-Al series}

Li Jianhong etc. [12] studied the effect of Gd on microstructure and mechanical properties of 
Mg-6Al-1.2Y-0.9Nd alloy. The results showed that, by adding the Gd alloy grain size is kept within a small range, the emergence of $\mathrm{Al}_{2} \mathrm{Y}, \mathrm{Al}_{2} \mathrm{Nd}, \mathrm{Al}_{2} \mathrm{Gd}$ three kinds of high melting point of precipitates in the alloy, and the morphological distribution of phases is closely related with the content of Gd. When the Gd content is 3.6wt.\%, strength of the alloy at room and elevated temperature reaches the maximum value.

\section{Mg-Zn series}

Zhang Xinping etc. [13] studied the Ga effect on the microstructure and mechanical properties of Mg-Zn-Gd alloy, the results of the study show that the content of $\mathrm{Zn}$ is constant, with the increase of Gd content in alloy second to meet changing, two secondary dendrite arm spacing decreases, the grain refinement, the intergranular microstructure transformation from granular, thin like to closed mesh. In the aspect of mechanical properties when the content of $\mathrm{Zn}$ invariant Gd content increased, tensile strength and elongation of the alloy increased, but the yield strength increased first and then decreased.

Li Jiehua of the Northwestern Polytechnical University studied the influence of rare earth element Gd on properties of Mg-Zn-Zr alloy, the results show that Gd can significantly improve the high temperature mechanical properties of the alloy. But when the Gd content reached the solid solubility limit value, the strength of the alloy began to decrease [14].

\section{Mg-RE series}

Wang Feng etc. [15] studied the Ca, Gd of Mg-6Gd-3Y-0.5Zr (GW63K) effect and properties of alloys. The results show that, addition of $\mathrm{Ca}$ or $\mathrm{Gd}$ can make the microstructure of alloy refined, and make the number of rare earth phase on the grain boundary significantly increase. Gd is mainly distributed in the grain boundaries of the rare earth phase, rare earth phase to short rod like or granular distribution in grain boundaries, the addition of Gd is more helpful to improve the high temperature strength of the alloy.

Li Quanan etc. [16] invented a kind of heat resistant rare earth magnesium alloys Mg-Gd-Y-Sm-Zr-Sb, the components: $8 \%-15 \% \mathrm{Gd}, 2 \%-5 \% \mathrm{Y}, 0.4 \%-4.5 \% \mathrm{Sm}, 0.3 \%-0.7 \% \mathrm{Zr}$, $0.3 \%-2 \% \mathrm{Sb}$, the remainder is $\mathrm{Mg}$. The heat resistant rare earth magnesium alloys has excellent creep resistance and high tensile strength, room temperature to $250^{\circ} \mathrm{C}$, with the tensile strength of the alloy abnormal temperature effect. When at a temperature of $250^{\circ} \mathrm{C}$ the maximum tensile strength of the alloy can reach $346 \mathrm{MPa}, 300^{\circ} \mathrm{C}$ the tensile strength is still up to 309MPa. Compared with the WE series for commercial magnesium alloys, it has the better strength at room temperature and high instantaneous temperature strength.

\section{Conclusions}

At present, the application research of Gd in high strength heat-resistant magnesium alloys, from the solid solution strengthening and precipitation strengthening of start, to improve the mechanical alloy properties at room temperature and high temperature and creep resistance properties. Despite the research of heat resistant magnesium alloys containing Gd has achieved some progress, but about Gd and other alloy elements interaction mechanism and quantitative analysis and forecast, Gd strengthening mechanism and creep strengthening mechanism of magnesium alloys, and the research of Gd containing magnesium alloys creep behavior and creep mechanism remains to be further in depth. In addition, excessive Gd may worsen the properties of magnesium alloys, Gd more expensive price makes the production cost greatly increased, is not conducive to commercial, so the development of low Gd high strength heat-resistant magnesium alloys is expected to become the future research direction. 


\section{Acknowledgement}

The project is supported by the National Natural Science Foundation of China (No. 51171059), Basic and Frontier Technologies Research Plan of Henan Province (No. 102300410018) and Program for Innovative Research Team (in Science and Technology) in University of Henan Province (No. 2012IRTSTHN008).

\section{References}

[1] Emley E F. Principles of magnesium technology[M]. New York: Pergamon Press, 1966:126-127

[2] Mordike B L, Ebert T. Magnesium properties, applications, potential[J]. Materials Science and Engineering, 2001, A302:37-45

[3] Friedrich H E, Mordike B L. Magnesium Technology: Metallurgy, Design Data, Applications [M]. Germany: springer, 2006:352

[4] Sun M, Wu G H, Wang W, et al. Research Progress of Mg-Gd Alloy[J]. Materials Review, 2009, 23(6):98-103

[5] Drits M E, Sviderskaya Z A, Rokhlin L L, et a1. Effect of alloying on the properties of Mg-Gd alloys[J]. Metal Science and Heat Treatment, 1979, 21(11-12):887-889

[6] Drits M E, Rokhlin L L, Oreshkina A A, et a1. Principles of alloying heat-resistant alloys based on magnesium[J]. Metalluary, 1982(5):98-103

[7] Rokhlin L L, Nikitina N I. Electron-microscopic investigation of the structure of decomposed supersaturated solid solution Mg-22wt\%Gd[J]. Physics of Metals and Metallography, 1986, 62(4):145-150

[8] Kamado S, Iwasawa S, Ohuchi K, et a1. Aging hardening characteristics and high temperature strength of Mg-Gd and Mg-Tb alloys[J]. Journa1 of Japan Institute of Light Metals, 1992, 42(12): 727-732

[9] Iwasawa S, Negishi Y, Kamado S, et a1. Age hardening characteristics and high temperature tensile properties of Mg-Gd and Mg-Dy alloys[J]. Journal of Japan Institute of Light Metals, 1994, $44(1): 3-8$

[10] Kubota K, Mabuchi M, Higashi K. Processing and mechanical of properties of fine-grained magnesium alloys[J]. Journal of Materials Science, 1999, 34: 2255.

[11] Gu S Z, Zhou X L, Li Y B, et al. Research Development of Mg-Gd-Y Alloy[J]. Materials Review, 2009, 23: 446-448

[12] Li J H. Effect of Rare-earth on Microstructure and High temperature Tensile Mechanical Properties of Mg-6Al Alloys[D], Henan University of Science and Technology ,2008

[13] Zhang X P, Yuan G Y, Liu Y, et al. Effects of Alloying Elements on the Microstructure and Mechanical Properties of Mg-Zn-Gd Alloys[J]. Special Casting \& Nonferrous Alloys, 2008, 28(11): 882-884

[14] Li J H, Jie W Q, Yang G L, et al. Effect of Gadolinium on Microstructure and the Mechanical Properties of Mg-Zn-Zr Cast Magnesium alloys[J]. 2008, 37(9): 1587-1591

[15] Wang F, Wang Z, Li L, et al. Effects of Ca and Gd on Microstructure and Mechanical Properties of Die Casting Mg-6Gd-3Y-0.5Zr Alloys[J]. Foundry, 2009, 58(10): 1026-1029

[16] Q.A Li, K.J. Li, Q. Zhang. Sm for ageing Mg-12Gd-2Y-0.5Zr the influence of the microstructure and mechanical properties[J]. Transactions of Metal Heat Treatment, 2011, 32(12): 84-88 